\title{
Unicornuate uterus with functional non communicating rudimentary horn: a refractory cause of dysmenorrhea
}

\author{
Manju Agarwal, Rakhee Soni*, Madhureema Verma
}

Department of Obstetrics and Gynecology, Jhalawar Medical College, Jhalawar, Rajasthan, India

Received: 04 November 2019

Revised: 03 December 2019

Accepted: 11 December 2019

\author{
*Correspondence: \\ Dr. Rakhee Soni, \\ E-mail: sonirakhee777@gmail.com
}

Copyright: () the author(s), publisher and licensee Medip Academy. This is an open-access article distributed under the terms of the Creative Commons Attribution Non-Commercial License, which permits unrestricted non-commercial use, distribution, and reproduction in any medium, provided the original work is properly cited.

\begin{abstract}
Mullerian duct anomalies are rare. Unicornuate uterus with a non-communicating rudimentary horn is a rare type of mullerian duct anomaly which occurs due to defective fusion of malformed duct with contralateral duct. The incidence is approximately 1:100000. Patient usually remain asymptomatic due to the absence of functional endometrium in most of the cases. If the rudimentary uterine horn has an endometrium lined uterine cavity and doesn't communicate externally then the signs and symptoms of obstructed menstruation appears, as soon as menarche begins. It will be associated with severe dysmennorhoea and hematometra. Other complications may be abdominal lump, chronic pelvic pain, infertility, endometriosis, adenomyosis and ectopic pregnancy in rudimentary horn. Authors are presenting a case of refractory dysmenorrhea with lump abdomen in a patient with unicornuate uterus with functional non communicating horn. In a patient with refractory dysmenorrhea mullerian duct anomaly should be kept as differential diagnosis.
\end{abstract}

Keywords: Dysmennorhoea, Functional endometrium, Hematometra, Mullerian duct anomalies, Non-communicating rudimentary horn, Unicornuate uterus

\section{INTRODUCTION}

The incidence of mullerain duct anomalies varies depending on whether one considers the general population or women being investigated for infertility. The incidence is $3-4 \%$ in fertile and infertile women, 5$10 \%$ in women with recurrent miscarriages, and greater than $25 \%$ in women with late miscarriages and preterm deliveries. ${ }^{1}$ Unicornuate uterus with a noncommunicating rudimentary horn is a rare type of mullerian duct anomaly which occurs due to defective fusion of malformed duct with contralateral duct. The incidence is approximately $1: 100000 .^{2}$ A close embryologic relation exists between the development of the urinary and reproductive organs. ${ }^{3}$ Renal tract malformations may be simultaneously present in women with mullerian duct malformations. Patient usually remain asymptomatic due to the absence of functional endometrium in most of the cases. If the rudimentary uterine horn has an endometrium lined uterine cavity and doesn't communicate externally then the signs and symptoms of obstructed menstruation appears, as soon as menarche begins. It will be associated with severe dysmennorhoea and hematometra. Other complications may be abdominal lump, chronic pelvic pain, infertility, endometriosis, adenomyosis and ectopic pregnancy in rudimentary horn.

\section{CASE REPORT}

Authors reported a case of 22-year-old married P1L1 admitted to SHKBM hospital of Jhalawar medical college 
with chief complaints of cyclic dysmennorhoea since menarche which has been gradually increased in intensity and lump abdomen for 6 months. She was operated 5 years ago for acute pelvic pain along with dysmenorrhea and lump abdomen. She had no record of the operation but on it seemed to be left adnexa removal according to her history. It might be endometrioma formed due to retrograde flow of menstruation or ovarian cyst or hematosalpinx. She attained menarche at 13 years of age, cycles 3-4/28-30 days, regular with normal flow. Her LMP was 1-6-19. She had visited many doctors for her symptoms but did not get any cure.

On general physical examination, no gross anomaly seen and her vitals were normal.

On per abdominal examination, vertical midline scar seen along with a lump of around 24 weeks arising from pelvis, deviating slightly to the left side of abdomen. Lump was firm in consistency with restricted mobility.

On per speculum examination, cervix and vagina was healthy, os was single, deviated to right side. Bulge was present on left and posterior fornix.

Per vaginal examination revealed uterus of 24-week size deviated to the left side with mobility restricted and movement of cervix was transmitting to lump, left and posterior fornix full.

\section{Laboratory values}

$\mathrm{Hb}-10$ gm, HCT- $34.5 \%$, WBC $-6.25 \times 103 / \mathrm{L}$, platelets $-256 \times 103 / \mathrm{L}$, UPT- negative.

Her abdominal sonography was suggestive of enlarged uterus with? pyometra? hematometra, right ovary normal, left ovary not visualized, left kidney not visualized.

Her MSCT scan was suggested grossly distended endometrial cavity with high density fluid in endometrial cavity suggestive of hematocolpos and absent left kidney. Both abdominal sonography and MSCT scan were not correlating with patient's history, as she delivered one baby normally one and half year back and has been having normal menstrual flow every month with severe dysmenorrhea so authors made a clinical diagnosis of unicornuate uterus with functional non communicating rudimentary horn, in which her menstrual blood was collecting leading to haematometra and lump abdomen and cause of cyclic dysmenorrhea.

Decision of exploratory laparotomy was taken after explaining the condition to patient and her attender.

On exploratory laparotomy, the unicornuate right unicornuate uterus with a non-communicating distended left rudimentary horn of around $25 \times 10 \mathrm{~cm}$ seen.

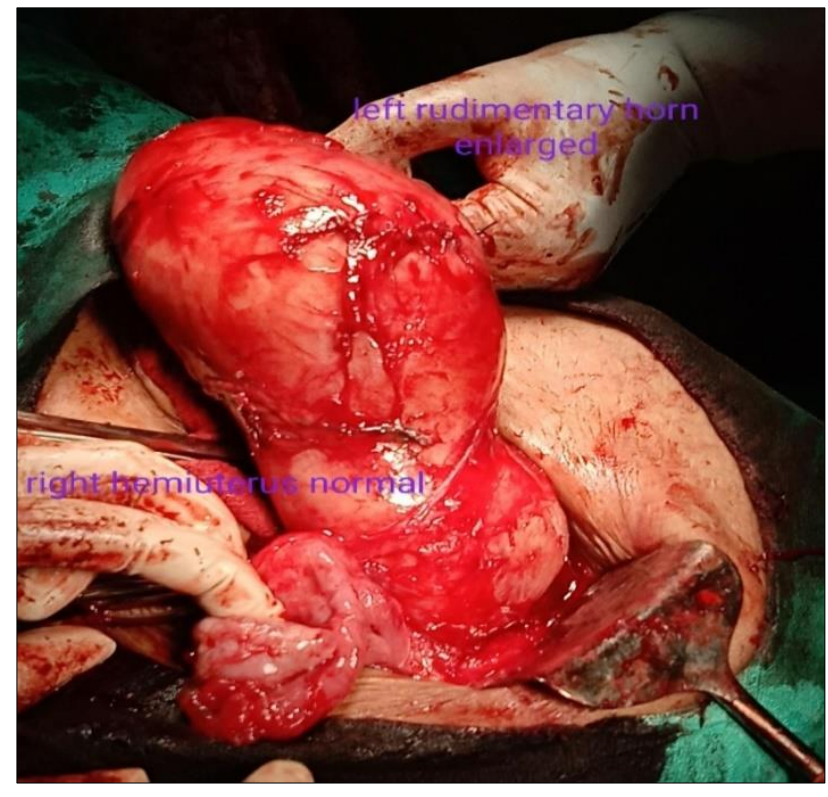

Figure 1: Right side normal hemi uterus with adenexa and left side rudimentary horn with haematometra.

Left sided adnexa was absent, consistent with history of salpingo-oopherectomy. Around $700 \mathrm{ml}$ of altered thick blood, brown in color was collected in that rudimentary horn. The right uterine horn was normal, with normal right tube, ovary and round ligament. Her left rudimentary horn was removed. Right unicornuate uterus left intact so she can conceive in future.

Cut section of the left hemi-uterus showed that the cavity was filled with dark coloured fluid (old blood).

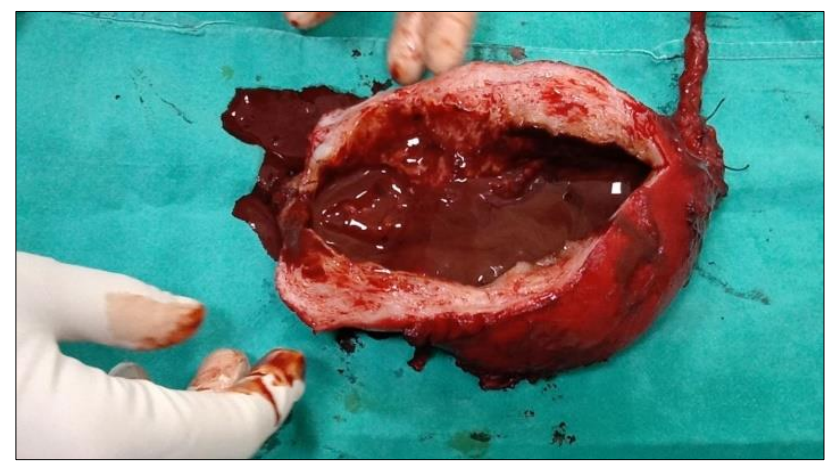

Figure 2: Cut section of rudimentary horn.

Histologically study confirmed- hematometra.

Patient withstood procedure well and had an uneventful post-operative period.

\section{DISCUSSION}

American fertility society has divided mullerian anomalies into several classes. Unicornuate uterus with non-communicating rudimentary horn are categorized as 
class II b4. Most rudimentary horn are noncommunicating $(90 \%)$.

A close embryologic relation exists between the development of the urinary and reproductive organs. Hence renal tract defects are likely to be found in women with mullerian duct malformations. Congenital absence of one kidney has been the most common urologic anomaly associated with obstructive uterovaginal anomalies. Women with one kidney and a malformed uterus have more than twice the risk of the development of gestational hypertension and late onset preeclampsia compared with those with a similar uterine anomaly but two normal kidneys. ${ }^{5}$

The uterine anomaly of this patient was missed initially, at the time of previous laparotomy which lead to obstruction of retrograde flow of menstruation. Her dysmennorhoea and hematometra exaggerated.

MRI is the gold standard for diagnosis of mullerian abnormalities.

\section{CONCLUSION}

The diagnosis and management of uterine anomalies are often a challenge for the gynaecologist. A high index of suspicion for the presence of uterine anomaly arises when patient complaint of refractory cyclical pelvic pain and adequate workup is mandatory to make a correct diagnosis. The main aim of surgical excision of symptomatic functional non communicating horn is pain relief. Laparotomy is the standard approach for such cases, but due to advantages of shorter hospital stay, small incisions and less post-operative pain, laproscopy has become the first choice. Simultaneous evaluation of renal system is mandatory due to high incidence of associated urological anomalies.

Funding: No funding sources

Conflict of interest: None declared

Ethical approval: Not required

\section{REFERENCES}

1. Acien P. Incidence of Müllerian defects in fertile and infertile women. Human Repro (Oxford, England). 1997;12(7):1372-6.

2. Priyanka, Shergill H, Bansal R, Aggarwal M. A rare case of unicornuate uterus with non-communicating rudimentary horn containing functional endomaterium. Int $\mathbf{J}$ Reprod Contracept Obstet Gynecol. 2018;7:5182-6.

3. Lawrence WD, Whitaker D, Sugimura H, Cunha GR, Dickersin GR, Robboy SJ. An ultrastructural study of the developing urogenital tract in early human fetuses. Am J Obstet Gynecol. 1992;167(1):185-93.

4. The American Fertility Society classifications of adnexal adhesions, distal tubal occlusion, tubal occlusion secondary to tubal ligation, tubal pregnancies, Mullerian anomalies and intrauterine adhesions. Fertil Steril. 1998;49:944-55.

5. Heinonen PK. Renal tract malformations associated with mullerian duct anomalies. Clin Obstet Gynecol Repord Med. 2018;4.

Cite this article as: Agarwal M, Soni R, Verma M. Unicornuate uterus with functional non communicating rudimentary horn: a refractory cause of dysmenorrhea. Int J Reprod Contracept Obstet Gynecol 2020;9:874-6. 